\title{
Reliability and Validity of the Turkish Version of the Revised American Pain Society Patient Outcome Questionnaire in Postoperative Patients
}

\author{
Aysun Keskin' (D, Gülten Sucu Dağ² ${ }^{\circledR}$, Debra B. Gordon ${ }^{3}$ \\ 'Department of Nursing, Dr. Burhan Nalbantoğlu State Hospital, Nicosia, North Cyprus \\ 2Department of Nursing, Faculty of Health Sciences, Eastern Mediterranean University, Famagusta, North Cyprus \\ ${ }^{3}$ Anesthesiology $\bar{\alpha}$ Pain Medicine Co-Director Harborview Integrated Pain Care Program University of Washington, USA
}

ORCID ID of the author: A.K. 0000-0002-III2-4I86; G.S.D. 0000-0003-4887-22I4; D.B.G. 0000-0003-1946-25I5.

Cite this article as: Keskin A, Sucu Dağ G, Gordon DB. Reliability and Validity of the Turkish Version of the Revised American Pain Society Patient Outcome Questionnaire in Postoperative Patients. Cyprus J Med Sci 2019; 4(3): 157-63.

\section{BACKGROUND/AIMS}

The aim of the present study was to evaluate the psychometric properties of the Turkish version of the Revised American Pain Society Patient Outcome Questionnaire (APS-POQ-R) in postoperative patients.

\section{MATERIAL and METHODS}

A descriptive, cross-sectional psychometric study design was used to examine the psychometrics of the Turkish APS-POQ-R among a convenience sample of 218 adult postoperative patients treated by five surgical departments in two hospitals. The 23-item English version of the questionnaire was translated into Turkish according to international guidelines. For the questionnaire, construct validity was analyzed with confirmatory factor analyses and known group validity. Cronbach's alpha was used to examine the questionnaire internal consistency reliability.

\section{RESULTS}

The Cronbach's alpha of the questionnaire was .91. Cronbach's alpha coefficients for the subscales were pain severity and sleep interference .87 , activity interference .92 , affective .95 , adverse effects .91 , and perception of pain care .50 .

\section{CONCLUSION}

The Turkish APS-POQ-R was found to have confirmatory factor structure and internal validity and construct reliability similar to the original instrument. The questionnaire appears to be useful to evaluate the quality of pain management in postoperative patients and can be used to guide the implementation of nursing interventions. Further investigation is warranted on the perceptions of care subscale.

Keywords: Patient outcomes, postoperative pain, psychometrics, reliability, revised American pain society patient outcome questionnaire

\section{INTRODUCTION}

Acute postoperative pain is a common clinical condition requiring an evidence-based, planned, and multimodal approach (I). Despite the increase in knowledge on the physiology and control of pain, most of the patients do not receive sufficient analgesia or pain control during the surgical period (2).

Data collected by the World Health Organization from 194 countries reveal that approximately 312.9 million major surgical operation occurred in 2012 (3). In the case of Turkey, the annual number of surgical operation is >8.6 million (4). According to the literature, the percentage of patients who suffer from severe pain during the first postoperative day ranges between $20 \%$ and $80 \%$ worldwide $(5,6)$ and between $60 \%$ and $77 \%$ in Turkey $(7)$. Inadequately treated postoperative pain delays recovery and discharge, which in turn decreases patient satisfaction (2).

Whenever possible, postoperative pain should be prevented and controlled. The aim of acute pain management is to prevent postoperative complications, speed up the recovery period, minimize the side effects of analgesics, and prevent 
acute pain from becoming chronic $(1,8)$. Effective pain management is a central concern of nursing. Inadequate pain management decreases patient satisfaction and may prolong the length of the recovery period and the risk of re-hospitalization (9-II).

Pain management is an important indicator of healthcare quality. Quality pain management is a multidimensional issue that starts with the proper evaluation of pain of the patients and their response to the treatment. Monitoring and evaluation of pain management quality by using the appropriate measurement tools are essential for the improvement of patient outcomes and pain management quality $(10,12)$.

Gordon et al. (12) identified measurable patient reported outcome domains to evaluate acute pain management quality. These include pain severity and relief; impact of pain on activity, sleep, and negative emotions; side effects of treatment and perceptions of the patients, such as helpfulness of the information received about pain treatment; ability to participate in pain treatment decisions; and satisfaction with the results of the treatment. To develop a standard measurement tool for quality improvement purposes that includes these dimensions, the researchers revised the American Pain Society Patient Outcome Questionnaire (APS-POQ) developed by the American Pain Society in 1991 (American Pain Society Quality of Care Committee, 1995). In the revised questionnaires, APS-POQ-R has been used to evaluate the impact of acute postoperative and medical condition-related pain in hospitalized adults and has been translated into 12 different languages (12-16), for example, Chinese, Australian, and Icelandic versions $(13,15,16)$.

Although there are various questionnaires in Turkish used to identify pain sources and severity (17-19), there is no measurement tool to evaluate the quality of pain management using patient reported outcomes together with pain treatments. Such a tool may aid the health professionals to evaluate the postoperative pain management quality, effects of pain on patient outcome, patients' activity and mood, and side effects of pain and pain management. This methodological study has been conducted to evaluate the reliability and validity of the Turkish version of the APS-POQ-R.

\section{Research Questions}

I. What is the reliability coefficient of the Turkish version of the APS-POQ-R?

2. Isw the confirmatory factor analysis in harmony with the preliminary factor structure?

\section{MATERIAL and METHODS}

This methodological study was conducted at the general surgery and orthopedics, urology, gynecology, and neurosurgery wards of two state hospitals in the Turkish Republic of Northern Cyprus. The study included participants aged $>18$ years, who underwent minor and major surgical operations, and who stayed at the hospital for at least $24 \mathrm{~h}$.

Studies on scale development, reliability, and validity suggest that the sample size should be at least 200 and 10 times the number of items (20). Based on these criteria, a total of 230 voluntary participants were included to our research. However, owing to the shortcomings in the data collection form of 12 patients, the study was conducted with the participation of 218 voluntary patients.

Data were collected between February 26, 2017 and June 22, 2017. Gordon et al. (12) collected data from patients who received treatment for at least $24 \mathrm{~h}$ in a hospital $72 \mathrm{~h}$ after the surgical operation. Patients answered a questionnaire on postoperative day 3. Patients who met the inclusion criteria were informed about the aims of the research. Written and verbal consents were obtained from the voluntary participants.

The researchers read the questions to the participants and recorded their responses. Descriptive data on age, gender, clinic, type and location of surgery, type of analgesics, and route of analgesics administration were obtained from the patient files and recorded to the Descriptive Characteristics Form. Data on pain management quality and patient outcome were collected by using the APS-POQ-R.

The APS-POQ-R is composed of 23 items that aim to measure the five dimensions of the pain management quality. Five subscales, which consisted of a total of 18 items, include pain severity and sleep interference (five items), activity interference (two items), affective (four items), adverse effects (four items), and perceptions of care (three items) subscales. Overall, the Cronbach's alpha of the original questionnaire was .86. Additional items in the questionnaire, including information about pain treatment options, the use of non-medication methods, and how often a doctor or nurse encouraged the use of non-medication methods, were evaluated from the subscales.

The responses to the two items on the estimate of percentage of time in severe pain and the pain relief in the first $24 \mathrm{~h}$ were measured according to their percentages that ranged between $0 \%$ and $100 \%$. The responses to the remaining 16 items of the five subscales were measured by the $0-10$ numeric rating scale, which was treated as a continuous scale. Additional items on the use of non-medication methods and receiving information about pain treatment options involved dichotomous yes/no responses. A "yes" response was followed by a request for a more specific response.

The APS-POQ-R was translated and retranslated according to international guidelines (2I). It was first translated into Turkish by two experts on the English and Turkish languages. Translation validity of the APS-POQ-R was evaluated by using a retranslation technique. The APS-POQ-R was translated back to English by two experts of the English language who did not see the original APS-POQ-R. Items in the retranslated APS-POQ-R were compared with those in the original scale, and expert opinion was used for evaluating translation validity. To maintain content validity, the scale was evaluated in line with the suggestions of nine clinicians and academicians from the clinics and departments of surgical nursing, basics of nursing, psychiatric nursing, anesthesiology, psychology, and internal medicine. Based on the suggestions, changes were made in three questions. For the "how much pain interfered or prevented you from" question, the expressions were changed from "did not intervene" and "completely intervened" into "did not prevent" and "completely prevented." In the questions "In the first 24 hours, how much pain relief have you received? Please circle the one percentage that 
best shows how much relief you have received from all of your pain treatments combined" and "Did you use any non-medicine methods to relieve your pain?", the expressions "analgesic" and "ice bag" were replaced with "pain treatment methods" and "cold application," respectively. The APS-POQ-R was modified based on expert opinion, and the questionnaire was finalized.

To evaluate expert opinion, Content Validity Index (CVI) was used (22). While assessing expert opinion, CVI was used, which was evaluated by calculating Item-Content Validity Index (I-CVI) and Scale-Content Validity Index (S-CVI). The I-CVI for each item and the S-CVI for the whole questionnaire were calculated. The I-CVI and S-CVI scores on nine expert opinions were .82 and .84 , respectively. I-CVI and S-CVI are suggested to be higher at .80 and .78 , respectively (22). The I-CVI and S-CVI scores for this research were .82 and .84 , respectively. This finding suggests that there is a consensus among the experts, and that the APS-POQ-R has a clear and intelligible content. Following the evaluation of expert opinion, the suggestions of an expert in the Turkish language were taken to adapt the scale into Turkish.

After maintaining translation and content validity, the APS$P O Q-R$ was administered on 50 voluntary participants to evalvate the extent to which the questions were clear and intelligible. Additionally, an evaluation form was prepared to receive feedback from the participants. The evaluation form consisted of statements, such as "explanations in the APS-POQ-R were clear," "it was easy to follow the APS-POQ-R," "questions in the APS-POQ-R were clear," and "questions in the APS-POQ-R were boring." The participants were asked to express their opinions on these statements by using a five-point Likert scale with categories that ranged from "strongly agree" to "strongly disagree." The analysis of the responses of the participants of the pilot study reveals that $99 \%$ of the participants found the Turkish version of the APS-POQ-R as clear and intelligible. Participants in the pilot study were excluded in the final sample.

\section{Statistical Analysis}

Data obtained were evaluated by using Statistical Package for the Social Sciences version 18.0 (SPSS Inc.; Chicago, IL, USA). Descriptive statistics were used to evaluate sample characteristics and pain management results. While evaluating the psychometric characteristics of the Turkish version of the APS-POQ-R, confirmatory factor analysis and known group validity for validity analysis and Cronbach's alpha coefficient and item-total correlation for reliability analysis were used.

The study was approved by the Scientific Research and Publication Ethics Committee of the Eastern Mediterranean University (ET00-2016-0I56), Ministry of Health (YTK.0.00-I/2013-16/7303). Written consent was obtained from the participant patients by using an "Informed Voluntary Consent" form. Written permission was also obtained from D.B. Gordon to translate the original APS-POQ-R into Turkish.

\section{RESULTS}

The average age of the participants in the sample of this research was $39.7 \pm 15.00$ years. In the present study, $70.6 \%$ of the participants were female, and $39.0 \%$ received treatment at the gynecology clinic. Approximately $52.8 \%$ of the participants un- derwent minor surgical operation, 93.1\% received non-steroidal anti-inflammatory drug (non-opioid), $80.0 \%$ were administered analgesics by intramuscular route, and $51.4 \%$ underwent prior operation (Table I).

Construct validity of the Turkish version of the APS-POQ-R was analyzed, and the results of confirmatory factor analysis in the modified model were shown to be acceptable. Chi-square/p value was $328.41 / 0.000$ ( $p<.05)$, chi-square degree of freedom was 2.67, root mean square error of approximation (RMSEA)/p value was $.088(p<.05)$, and standardized root mean square residual (SRMR) value was .12. Adjusted goodness of fit index (AGFI), comparative fit index (CFI), non-normed fit index (NNFI), and goodness of fit index (GFI) that were created to test the resultant model were $.80,96, .95$, and .86 , respectively, further supporting that the model was acceptable. When the factor loads of the items of the APS-POQ-R were analyzed, we found that the item "allowed to participate in decisions about pain treatment" had a factor load of .17, whereas the factor loads of the remaining 17 items ranged between .56 and .96 (Figure I).

Construct validity of the APS-POQ-R was analyzed by using known group validity. Gender, age, prior surgical experience,

\begin{tabular}{|c|c|c|}
\hline Variables & $N$ & $\%$ \\
\hline \multicolumn{3}{|l|}{ Age } \\
\hline$\leq 60$ years & 193 & 88.5 \\
\hline$>60$ years & 25 & 11.5 \\
\hline \multicolumn{3}{|l|}{ Gender } \\
\hline Female & 154 & 70.6 \\
\hline Male & 64 & 29.4 \\
\hline \multicolumn{3}{|l|}{ Location of surgery } \\
\hline Abdomen/anorectal & 144 & 66.1 \\
\hline Orthopedics & 58 & 26.6 \\
\hline Head/neck/lumbar & 16 & 7.3 \\
\hline \multicolumn{3}{|l|}{ Type of surgery } \\
\hline Minor surgery & 115 & 52.8 \\
\hline Major surgery & 103 & 47.2 \\
\hline \multicolumn{3}{|l|}{ Type of analgesic } \\
\hline Opioid & 7 & 3.2 \\
\hline NSAID & 203 & 93.1 \\
\hline Opioid+NSAID & 8 & 3.7 \\
\hline \multicolumn{3}{|c|}{ Route of administration of analgesics } \\
\hline IV & 43 & 13.0 \\
\hline IM & 178 & 80.0 \\
\hline Oral & 16 & 7.0 \\
\hline \multicolumn{3}{|l|}{ History of surgery } \\
\hline Yes & 112 & 51.4 \\
\hline No & 106 & 48.6 \\
\hline Total & 218 & 100.0 \\
\hline
\end{tabular}




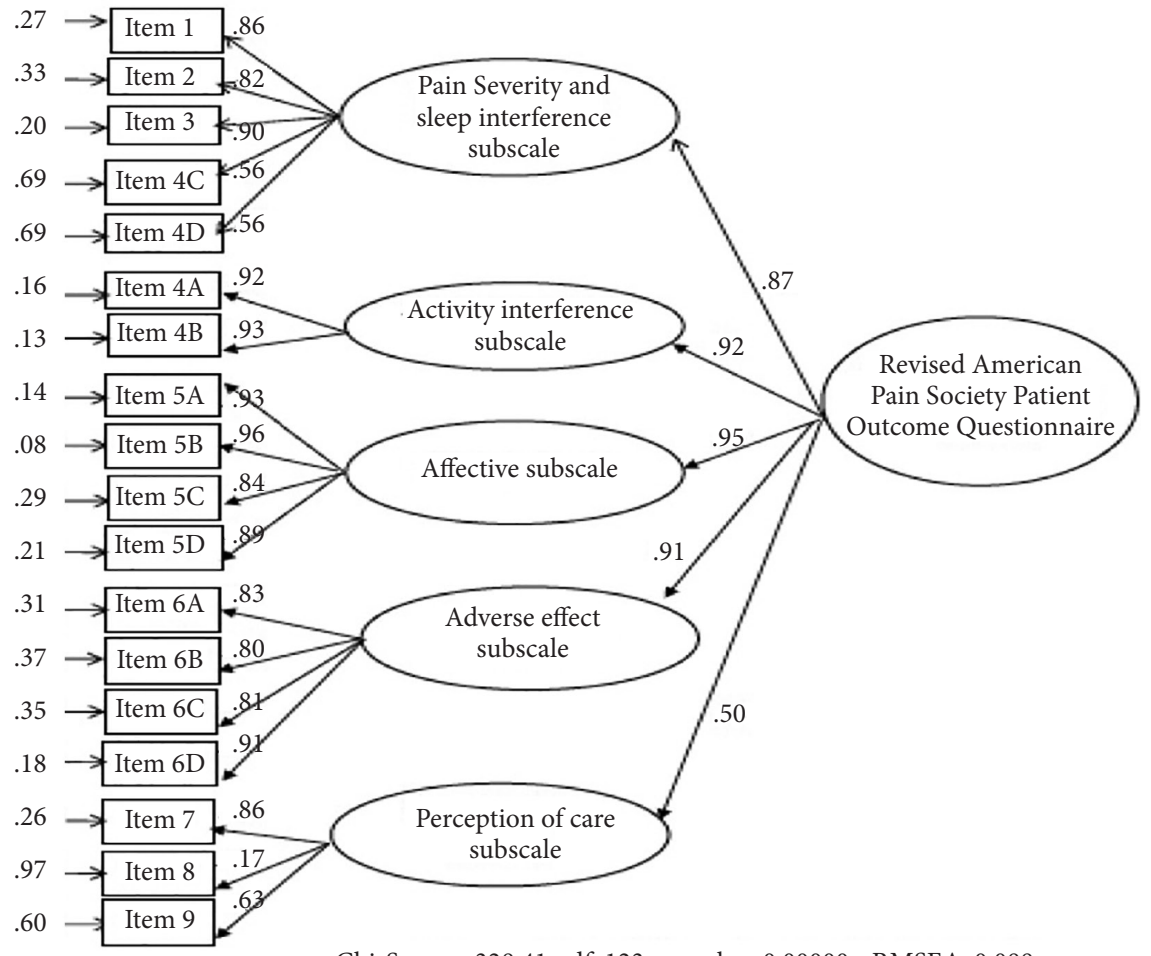

Chi-Square: 328.41 df: 123 p-value: 0.00000 RMSEA: 0.088

\section{FIGURE I. Confirmatory factor analysis of APS-POQ-R: path coefficients and error variances $(\mathrm{N}=218)$}

TABLE 2. Mean differences of APS-POQ-R subscales in known group patients ( $N=218$ )

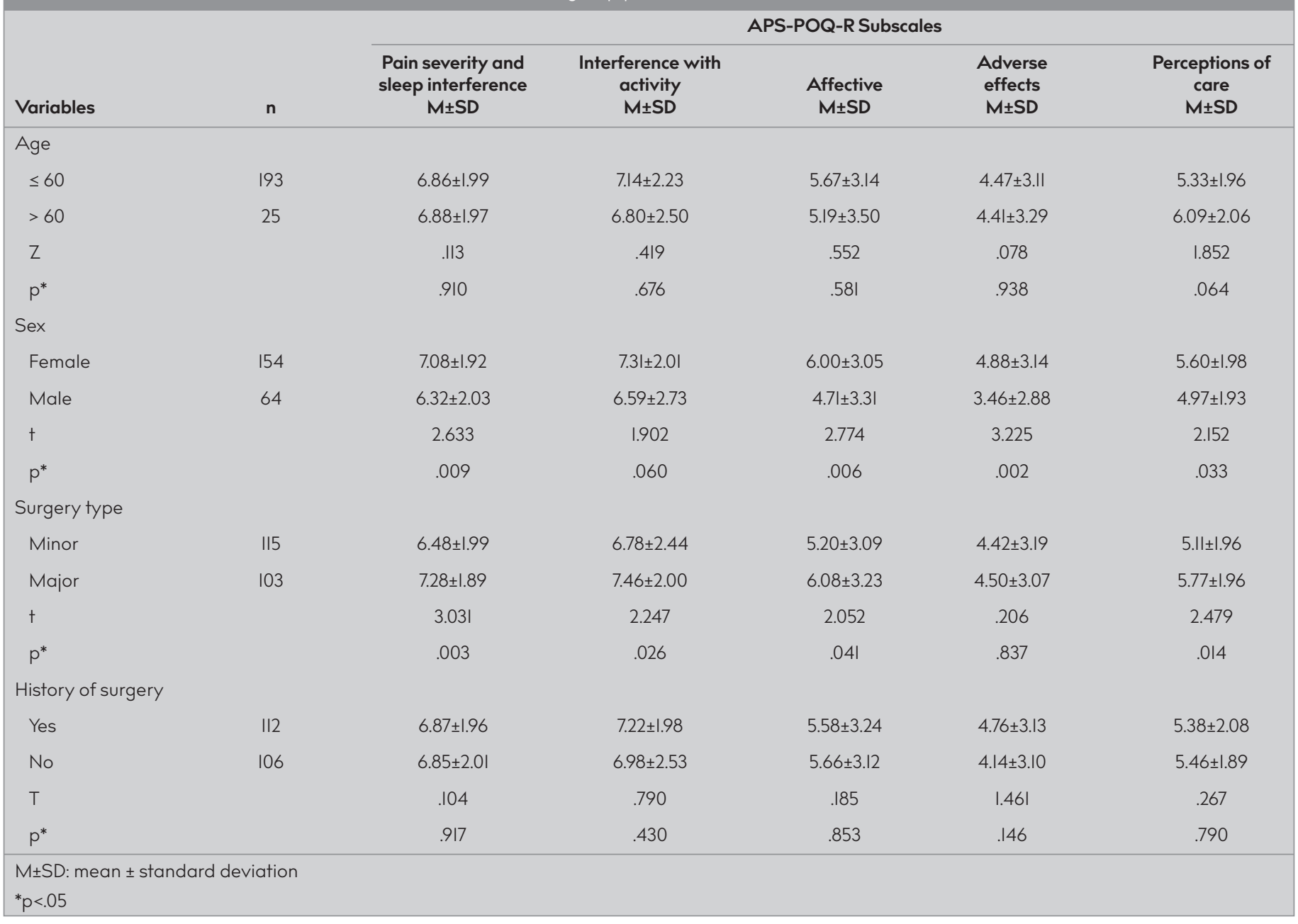


type of surgical operation (minor-major), and average scores of the subscales of the APS-POQ-R were evaluated (Table 2). The analysis of the relationship between gender and the average scores of the subscales reveals a significantly meaningful relationship between being female and the subscales of pain severity and sleep interference, affective, and adverse effects $(p<.01)$. On the other hand, the average score obtained by the female participants from the perceptions of care subscale was meaningfully higher than that by all participants $(p<.05)$. Although the average scores obtained by the female participants from the activity interference subscale are higher than those by the male participants, the relationship was not statistically meaningful ( $p>$.05).

The analysis of the relationship between age and prior surgical experience of the participants and the average scores of the subscales of the APS-POQ-R reveals no meaningful relationship between these variables ( $p>.05$ ). Compared with those who had minor surgical operation, participants who underwent major surgical operation had significantly meaningful scores from pain severity and sleep interference subscale $(p<.0 \mathrm{O})$ and meaningful scores from activity interference, affective, and perceptions of care subscales $(p<.05)$. On the other hand, the relationship between the type of surgery and adverse effects subscale was not statistically meaningful ( $p>.05$ ).

The internal consistency reliability of the APS-POQ-R is shown in Table 3. Cronbach's alpha coefficient of the 18 items of the APS-POQ-R was .91. Cronbach's alpha coefficients for the subscales of the APS-POQ-R were .87 for pain severity and sleep interference, .92 for activity interference, .95 for affective, .91 for adverse effects, and .50 for perception of pain care. Cronbach's alpha if the item was deleted for the APS-POQ-R was between 90 and 92, whereas item-total correlation was between .27 and .83 and was positive and statistically highly meaningful $(p<.01)$ (Table 3).

Descriptive statistics of additional items of the APS-POQ-R are shown in Table 4. Accordingly, $75.7 \%$ of the patients stated that they did not receive information about pain treatment options. For participants who expressed that they received information about pain treatment options, the average score for the additional item on the helpfulness of the information was $6.91 \pm 2.02$. In addition, $56.4 \%$ of the participants stated that they did not

TABLE 3. Item to total correlations and Cronbach's alpha $(\mathrm{N}=218)$

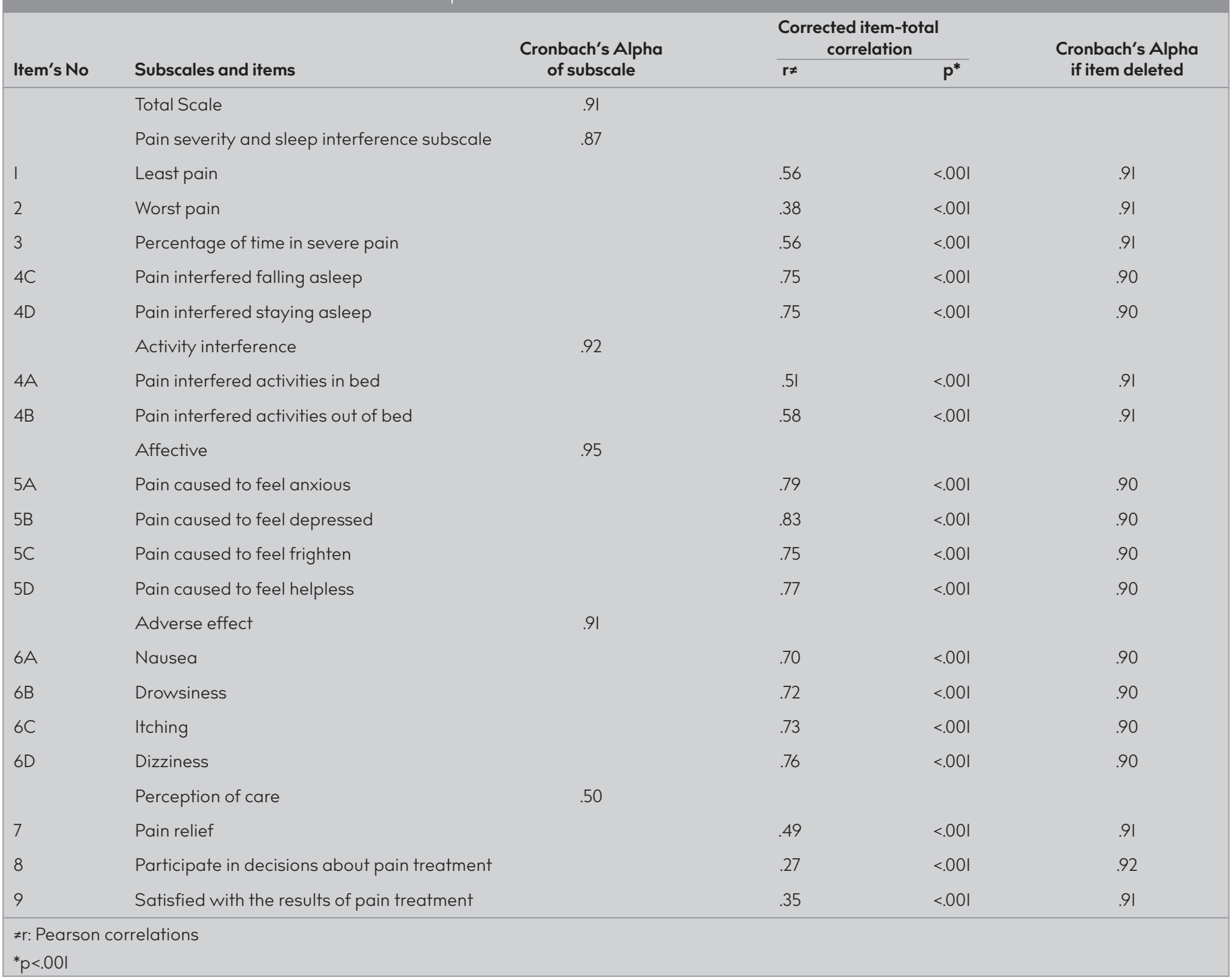


TABLE 4. APS-POQ-R descriptive statistics of other items ( $N=218)$

\begin{tabular}{|c|c|c|}
\hline Items & $\mathbf{n}$ & $\%$ \\
\hline \multicolumn{3}{|c|}{ Did you receive information about pain treatment options? } \\
\hline Yes & 53 & 24.3 \\
\hline \multirow[t]{2}{*}{ No } & 165 & 75.7 \\
\hline & Min-Max & $\mathrm{M} \pm \mathrm{SD}$ \\
\hline \multirow[t]{2}{*}{ How helpful information was if received? $(n=53)^{a}$} & $3-10$ & $6.91 \pm 2.02$ \\
\hline & $\mathrm{n}$ & $\%$ \\
\hline \multicolumn{3}{|l|}{ Did you use any nonmedication methods? } \\
\hline Yes & 95 & 43.6 \\
\hline No & 123 & 56.4 \\
\hline \multicolumn{3}{|l|}{ Used non pharmacological methods $(n: 95)^{b}$} \\
\hline Deep breathing & 39 & 41.1 \\
\hline Walking & 22 & 10.2 \\
\hline Praying & 16 & 7.8 \\
\hline Cold pack & 13 & 7.2 \\
\hline Listen to music & 9 & 8.5 \\
\hline Heat & 8 & 8.4 \\
\hline Distraction (Watching Tv, reading etc.) & 19 & 20.3 \\
\hline \multicolumn{3}{|c|}{ Did a doctor or nurse encourage nonmedication methods? } \\
\hline Never & 191 & 87.6 \\
\hline Sometimes & 18 & 8.3 \\
\hline Often & 9 & 4.I \\
\hline Total & 218 & 100 \\
\hline \multicolumn{3}{|c|}{$\begin{array}{l}\text { Max: maximum score; Min: minimum score; } M \pm S D \text { : mean } \pm \text { standard } \\
\text { deviation }\end{array}$} \\
\hline \multicolumn{3}{|l|}{ aThe averages are calculated on 53 people $(n=53)$} \\
\hline \multicolumn{3}{|c|}{$\begin{array}{l}\text { bMore than one option is marked. Percentages are calculated over } 95 \\
\text { people }(n=95)\end{array}$} \\
\hline
\end{tabular}

use non-medication methods. For participants who expressed that they used non-medication methods ( $n=95), 41.1 \%$ stated that they used deep breath method, and $87.6 \%$ said that the doctor or nurses did not encourage non-medication methods.

\section{DISCUSSION}

The present study, which originated from the need for the development of a measurement tool in Turkish to evaluate pain management quality and include patient reported outcomes, adapted the APS-POQ-R into Turkish (12). The items of the APS$P O Q-R$ were first translated into Turkish, and the translation and content validity of the Turkish version were evaluated. Next, the psychometric characteristics, internal consistency, item reliability, and construct validity of the APS-POQ-R were evaluated.

Studies that have been conducted to adapt the existing questionnaires into different cultures and languages suggest the use of confirmatory factor analysis to analyze construct validity (23, 24). In line with the suggestions in the literature, confirmatory factor analysis was conducted to evaluate the construct validity of the APS-POQ-R. Factor load of the item "allowed to participate in decisions about pain treatment" was .17, whereas the factor loads of the remaining 17 items ranged between .56 and
.96 (Figure 1). Factor loads of the items in the subscales were suggested to be equal to the factor loads and at least .30 (23). With the exception of the eighth item, all of the items in the Turkish version of the APS-POQ-R had a factor load >.30. Low factor load for the eighth item on allowing the patients to participate in decisions about pain treatment indicates that the participation of the patients and their relatives in treatment procedures is not common in the Turkish hospitals included in the present study. An indication that the culture of healthcare in these hospitals needs to improve should include the patient in treatment decisions.

While evaluating confirmative factor analysis, goodness of fit analysis is expected to be at normal levels. For a reasonable model, chi-square goodness of fit test should not be meaningful. This value may be achieved when the sample size is greater. Owing to this reason, in place of chi-square goodness of fit, chi-square value is divided by degree of freedom. The model is compatible if the value obtained is $<2$, whereas the model is considered to be at acceptable compatibility levels if the value is $<5$ (23). This value in the confirmatory factor analysis of the Turkish version of the APS-POQ-R was 2.67, indicating an acceptable compatibility level.

Another goodness of fit test that is frequently used is the RMSEA. This test suggests that an RMSEA score $\leq .08$ and a $p$ value $>.05$ indicate goodness of fit $(23,24)$, and that an RMSEA score $\leq .10$ shows low levels of goodness of fit (23). The present study, which calculated the RMSEA value as meaningful and .088 $(p<.001)$, found that the compatibility for the factorial structure was weak but at acceptable limits. A value of SRMR $<.10$ and the values of CFI and NNFI $\geq 0.90$ indicate goodness of fit (23). A valve $>.95$ indicates goodness of fit, whereas a value $>.90$ indicates acceptable goodness of fit $(23,24)$. The present study found that the CFI and NNFI values were .96 and .95, respectively, indicating goodness of fit. On the other hand, the SRMR value was close to but higher than the acceptable scores. This result may be related with the high factor load of the eighth item, which had low average and path coefficient. GFI and AGFI scores $\geq .90$ indicate an acceptable goodness of fit, whereas those scores $\geq 0.95$ refer to perfect goodness of fit (24). The AGFI $\geq .80$ and the GFI $\geq .85$ indicate goodness of fit (25). The present study found that the GFI was .86, and that the AGFI was .80, which, in turn, indicated the construct validity of the Turkish version of the APS-POQ-R.

Internal consistency of the findings was analyzed by using Cronbach's alpha coefficient and item-total correlation. Cronbach's alpha coefficient, which measures the homogeneity of the items of a scale, is generally considered as the best indicator of reliability (22). Cronbach's alpha coefficient for the APS-POQ-R was .91 and ranged between .50 and .95 for the subscales of the APS-POQ-R (Table 4). This finding suggests that the internal consistency of the first four subscales of the APS-POQ-R is significantly high. The original APS-POQ-R had a Cronbach's alpha of .86 , which ranged between .63 and .83 for its subscales (12). The analysis of the adaptations of the APS-POQ-R reveals that the Chinese version of the APS-POQ-R had a Cronbach's alpha coefficient of .73, with the values that ranged between .49 and .82 for the subscales (15). Cronbach's alpha coefficients of the scale and subscales of the APS-POQ-R were .13 and .86 for the Icelandic version (16) and .67 and .63-.74 for the Australian 
version (13), respectively. Moreover, Cronbach's alpha coefficient for the perceptions of care of the Australian version of the APS-POQ-R was .72 (I3). The review of the cross-cultural literature adaptation studies suggests that the coefficient for this subscale changed according to the sample and culture. Except for the perceptions of care subscale, the Turkish version of the APS-POQ-R had high Cronbach's alpha coefficients. Low reliability of the perceptions of care subscale is closely related with the fact that the eighth item in the APS-POQ- $R$ is not widely practiced in Turkey so that it decreases internal consistency. Additionally, the characteristics of the sample, cultural differences, and differences in healthcare services may be other reasons.

The present study found that the Turkish version of the APS$P O Q-R$ is a reliable and valid measurement tool to evaluate the patient scores and pain management quality for patients who underwent surgical operation and for nursing process planning. Further research is warranted to better understand the perceptions of care subscale using a larger sample size. Additionally, the Turkish version of the APS-POQ-R may be used to test the efficiency of the attempts to improve pain management quality.

Ethics Committee Approval: Ethics committee approval was received for this study from Eastern Mediterranean University ethics committee. (Approval Date: 04.II.2016, Approval Number: ETK00-2016-0156).

Informed Consent: Written informed consent was obtained from all individual participants included in the study.

Peer-review: Externally peer-reviewed.

Author Contributions: Concept - A.K., G.S.D.; Design - A.K., G.S.D.; Supervision - G.S.D.; Resources - D.B.G.; Data Collection and/or Processing - A.K., G.S.D.; Analysis and/or Interpretation - A.K., G.S.D.; Literature Search - A.K., G.S.D.; Writing Manuscript - A.K., G.S.D., D.B.G.; Critical Review - G.S.D., D.B.G.

Acknowledgements: We also thank Saniye Çimen for her suggestion regarding the statistical methods

Conflict of Interest: The authors have no conflicts of interest to declare.

Financial Disclosure: The authors declared that this study has received no financial support.

\section{REFERENCES}

I. Gordon, DB, de Leon-Casasola OA, Wu CL, Sluka KA, Brennan TJ, Chou R. Research gaps in practice guidelines for acute postoperative pain management in adults: findings from a review of the evidence for an American Pain Society Clinical Practice Guideline. J Pain 2016;17(2):158-66. [CrossRef]

2. Meissner W, Coluzzi F, Fletcher D, Huygen F, Morlion B, Neugebauer E, et al. Improving the management of post-operative acute pain: Priorities for change. Curr Med Res Opin 2015; 3I(II): 2I3I-43. [CrossRef]

3. Weiser TG, Haynes AB, Molina G, Lipsitz SR, Esquivel MM, UribeLeitz $T$, et al. Size and distribution of the global volume of surgery in 2012. Bull World Health Organ 2016; 94(3): 201-9. [CrossRef]

4. Mollahaliloğlu S, Bașara BB, Eryılmaz Z. Health Statistics Yearbook 2010. School of Public Health, Refik Saydam Hygiene Center Presidency, Ministry of Health of Turkey, Ankara, 20ll. Available from: http://istanbulsaglik.gov.tr/w/anasayfalinkler/belge/bakanlikistatistik/istatistik20l0.pdf
5. Lorentzen $\mathrm{V}$, Hermansen IL, Botti M. A prospective analysis of pain experience, beliefs and attitudes, and pain management of a cohort of Danish surgical patients. Eur J Pain 2012; 16(2): 278-88. [CrossRef]

6. Maier C, Nestler N, Richter H, Hardinghaus W, Pogatzki-Zahn E, Zenz M, et al. The quality of pain management in German hospitals. Dtsch Arztebl Int 20I0; 107(36): 607. [CrossRef]

7. Ayhan F, Kursun Ș. Experience of Pain in Patients Undergoing Abdominal Surgery and Nursing Approaches to Pain Control. IJCS 2017; 10(3): 1456-66.

8. Glowacki D. Effective Pain Management and Improvements in Patients' Outcomes and Satisfaction. Crit Care Nurse 2015; 35(3): 3343. [CrossRef]

9. Bruckenthal P, Simpson MH. The Role of the Perioperative Nurse in Improving Surgical Patients' Clinical Outcomes and Satisfaction: Beyond Medication. AORN Journal 2016; 104(6): 17-22. [CrossRef]

10. Gan TJ. Poorly controlled postoperative pain: prevalence, consequences, and prevention. J. Pain Res 2017; 10: 2287-98. [CrossRef]

II. Garimella V, Cellini C. Postoperative pain control. Clin Colon Rectal Surg 2013; 26(3): 19I-6. [CrossRef]

12. Gordon DB, Polomano RC, Pellino TA, Turk DC, McCracken LM, Sherwood G, et al. Revised American Pain Society Patient Outcome Questionnaire (APS-POQ-R) for quality improvement of pain management in hospitalized adults: preliminary psychometric evaluation. J Pain 20I0; II(II): I172-86. [CrossRef]

13. Botti M, Khaw D, Jørgensen EB, Rasmussen B, Hunter S, Redley B. Cross-cultural examination of the structure of the revised american pain society patient outcome questionnaire (APS-POQ-R). J Pain 2015; 16(8): 727-40. [CrossRef]

14. Mandell MS, Smith AR, Dew MA, Gordon DB, Holtzman S, Howell $T$, et al. Early postoperative pain and its predictors in the adult to adult living donor liver transplantation cohort study (A2ALL). Transplant 2016; 100(II): 2362. [CrossRef]

15. Wang H, Sherwood GD, Gong Z, Ren L, Liu H. Reliability and Validity of the Chinese Version of the Revised American Pain Society Patient Outcome Questionnaire in Postoperative Patients. Pain Manag Nurs 2017; I8(2): II0-20. [CrossRef]

16. Zoëga S, Ward S, Gunnarsdottir S. Evaluating the quality of pain management in a hospital setting: testing the psychometric properties of the Icelandic version of the revised American Pain Society patient outcome questionnaire. Pain Manag Nurs 2014; I5(I): 143-55. [CrossRef]

17. Dicle A, Karayurt Ö, Dirimeșe E. Validation of the Turkish version of the Brief Pain Inventory in surgery patients. Pain Manag Nurs 2009; I0(2): 107-I3. [CrossRef]

18. Eti Aslan F. Sensitivity and selectivity of the visual analog and the verbal rating scale in the assesment of postoperative pain. Journal of The Turkish Society of Critical Care Nurse 2004; I: I-6.

19. Vatansever NA, Akansel N. Validation study of the strategic and clinical quality indicators in postoperative pain management questionnaire in Turkish surgery patients. Pain Manag Nurs 2014; 15(4): 87I-80. [CrossRef]

20. Streiner DL, Kottner J. Recommendations for reporting the results of studies of instrument and scale development and testing. J Adv Nurs 2014; 70(9): 1970-9. [CrossRef]

21. Jones PS, Lee JW, Phillips LR, Zhang XE, Jaceldo KB. An adaptation of Brislin's translation model for cross-cultural research. Nurs Res 200l; 50(5): 300-4. [CrossRef]

22. Polit DF, Beck CT. The content validity index: are you sure you know what's beingg reported? Critique and recommendations. Res Nurs Health 2006; 29(5): 489-97. [CrossRef]

23. Harrington D. Confirmatory factor analysis. Newyork, USA: Oxford University Press; 2009. [CrossRef]

24. Simsek OF. Introduction to structural equality modeling: Basic principles and lisrel applications. Ankara: Ekinoks Press; 2007.

25. Cokluk Ö, Șekercioğlu G, Büyüköztürk Ș. Multivariate statistics for social sciences: SPSS and LISREL applications. Pegem Academy; 2014. 